\title{
Elementos para el análisis de la política exterior
}

\section{Nota Preliminar}

El origen de este ensayo es la experiencia acumulada en el desarrollo de un proyecto de cooperación con las instituciones de servicio exterior de los países latinoamericanos, encomendado a partir de 1986 por el PNUD al RIAL. Las visiones recogidas en la primera etapa. nos enseñaron que el mejoramiento de los servicios exteriores y de la calidad de la política exter:or, depende muy fundamentalmente del desarrolio de una función que es como la esencia misma de la profesión del diplomático y que podría denominarse análisis y planificación de la política exterior. También puso de manifiesto el desequilibrio existente en la capacidad de que disponen en esta materia los servicios exteriores de los países avanzados y de los latinoamericanos. Nos enseñó también que el estudio académico de las relaciones internacionales no coincide y, muchas veces, no aporta antecedentes muy valiosos para el análisis y la planificación de la política exterior de los paises en situaciones reales.

Este ensayo es esencialmente preliminar y metodológico. Sin embargo, no quisiera dejar de señalar desde un comienzo media do. cena de factores. "reales" de los cuales depende a nuestro juicio la orientación, la calidad y el vigor de una política: (1) su visión acerca de las características que presenta el sistema internacional en un momento determinado y de las oportunidades y limitaciones que plantea; (2) de su relación con la sociedad y con la historia, es decir, con la estructura social, la cultura política y el régimen de gobierno heredados del pasado histórico y, lo que es más importante, con su visión respecto del futuro; (3) las principales áreas de articulación externa de cada país, que definen los intereses que integrarán su agenda internacional, y la jerarquía existente entre los mismos; (4) el peso interno de la política exterior, esto es, la importancia que ésta tiene en la estrategia de desarrollo; (5) el hecho de cuán activa o pasiva es esa política y (6) la organización institucional con que cuenta el país para formularla y llevarla a cabo. De- 
bido al carácter metodológico que tienen estas notas, dichos aspectos "reales" no se analizarán en forma sistemática. Con todo, se los enuncia aquí para ulteriores reflexiones.

Desde un punto de vista metodológico, tres son, siempre a nuestro juicio, las grandes cuestiones que definen y diferencian la política exterior de los países. En primer lugar, la agenda internacional de cada país, es decir, los intereses concretos que persiguen en su accionar externo. En segundo lugar, sus objetivos, es decir, la posición que ese país desea alcanzar o el estado de cosas que pretende lograr a través de la satisfacción de sus intereses. En tercer lugar, el "estilo" que caracteriza la formulación y la aplicación de esa política (por ejemplo, si es más activa o más pasiva).

La percepción de que en América Latina hay pocos estudios sobre análisis y planificación de la política exterior, nos indujo a iniciar dichas reflexiones con un primer esfuerzo encaminado a identificar los principales elementos que deben ser empleados en este proceso a partir del relevamiento de la literatura producida en los pafses avanzados a la cual tuvimos acceso. Estos elementos, más refinados y más integrados en la realidad, deberían servir, por lo menos, para que los esfuerzos destinados a superar la ausencia de una política exterior no corran siempre el peligro de caer en la repetición de un repertorio de generalidades o de mitos como la no-intervención, el anti-imperialismo, la no-alineación, el tercer-mundismo o la integración latinoamericana, y permitan proponer metas más actualizadas y concretas.

\section{Algunos Aspectos Conceptuales}

A manera de introducción nos referiremos a la importancia que reviste el tema, al estado actual de la disciplina y a algunas definiciones esenciales para abordar esta materia.

Dentro de la evolución de las Giencias Sociales en América Latina los estudios internacionales se iniciaron con considerable retraso y continúan estando relativamente poco desarrollados ${ }^{1}$. Con todo, su tardío y precario desarrollo contrasta con la casi total ausencia de trabajos sobre análisis de la política exterior. Cabe señalar aqú desde un comienzo que el estudio de las relaciones internacionales de un país determinado (o a nivel global), no proporciona necesariamente antecedentes útiles para analizar su polftica exterior ni la de sus principales interlocutores.

${ }^{1}$ Ver L. Tomassini (ed.), Relaciones Internacionales en la América Latina (México: Fondo de Cultura Económica, 1981), R. Perina (ed.), Los Estudios Internacionales y América Latina y el Caribe (Buenos Aires: GEL, 1985) y A. Barros (ed.), Directorio de Centros Latinoamericanos de Estudios Internacionales (2a edición, 1987). 
Varios factores han contribuido a llamar la atención sobre la importancia de dicho análisis. Uno de los rasgos centrales de la evo-lución de los países latinoamericanos durante los últimos quince años radica en la creciente influencia que han adquirido en ellos los factores externos como resultado, por una parte, de la progresiva integración internacional de esos países y, por la otra, de la creciente complejidad que presenta el escenario internacional. De hecho los problemas más graves que enfrentan en la actualidad estos países inciden en el sector externo de sus economías y en su política exterior. Ello ha impuesto nuevas responsabilidades a las instituciones de servicio exterior de esos países con respecto a una gama de problemas mucho más amplia y más compleja que en el pasado. Como consecuencia de lo anterior, tiende a cerrarse la brecha que tradicionalmente existió entre el manejo de los asuntos políticos y el de las relaciones financiewas, comerciales y tecnológicas con el resto del mundo, desdibujándose aś aquella diplomacia de "doble vía" en virtud de la cual todas estas cuestiones que no constituían "la alta política", quedaban enteramente entregadas a agencias distintas de las cancillerías. Al mismo tiempo, el incremento de la interdependencia en las relaciones entre los estados ha dado lugar a una tendencia hacia el empleo de una diplomacia multilateral o el manejo colectivo de problemas internacionales, lo cual plantea desafíos adicionales a las cancillerias. Por último, debe señalarse el ensanchamiento de los márgenes de incertidumbre creados por las turbulencias registradas en el plano de la política internacional y de la economía mundial, como otro factor que hace necssario agudizar la capacidad de previsión de dichos organismos.

Todas estas circunstancias comprometen la capacidad de esos servicios para planificar la política exterior, para organizar sistemas adecuados de adopción de decisiones, y para implementarlas en forma eficaz, coherente y oportuna a las situaciones a que ellas se refieren.

En estas notas se postula la existencia de un estrecho vinculo entre (a) el análisis de la politica exterior, (b) los sistemas de información de que disponen los servicios respectivos, (c) la planificación de esa política, (d) los procesos de adopción de decisiones y, (e) los mecanismos para implementar dichas decisiones.

En un documento reciente sobre la materia, un destacado experto sobre el tema formulaba las siguientes proposiciones:

a) Los funcionarios de mayor rango a nivel decisorio, usualmente carecen del equipamiento cognitivo necesario para comprender y analizar las situaciones actuales y previsibles que podrfan afectar la política exterior.

b) Algunos conocimientos relevantes sobre la materia se encuen- 
- tran disponibles y pueden ser canalizados hacia los que formulan la política exterior a un costo factible y razonable:

c) Los responsables de dicha política, expuestos a esos conocimientos, por lo general responden favorablemente y los consideran muy útiles, dentro de los limitados propósitos de tales iniciativas ${ }^{2}$.

En cuanto al estado de los estudios sobre política exterior, cabe señalar que no sólo existe una profunda brecha entre la experiencia acumulada en los países desarrollados sobre la materia y la falta de aportes que se observa en América Latina, sino también entre los países anglo-sajones y las naciones continentales europeas dentro del primero de estos grupos, caracterizándose estas últimas poiun enfoque menos preciso y más generalista, histórico o político, de lás cuestiones técnicas involucradas en este tipo de análisis.

También existen considerables diferencias entre la importancia asignada en los Estados Unidos y en Gran Bretaña al análisis de las polfticas públicas, en general, y de la política exterior, en particular. "El análisis de las políticas como una disciplina separada - que involucra a cientistas políticos y economistas entre otros- no ha echado raíces en Gran Bretaña; el análisis de políticas, no se enenseña : en las universidades británicas, al menos bajo ese nombre; los analistas políticos no constituyen una categoría reconocida dentro del servicio civil, como en los Estados Unidos - afirma un informe sobre la materia-. La pérdida, según sospecho, es para Gran Brëtaña"3.

Además de estas diferencias en cuanto a la importancia asignada al análisis de la política exterior entre ambos países, existen significativas diferencias de enfoque. Ast, por ejemplo, se ha señalado que la naturaleza más cerrada đel proceso de adopción de decisiones in Gran Bretaña, ha tendido a concentrar el análisis de las politicạs dentro del ámbito de la Administración Pública, mientras que 1a mayor dispersión de las agencias que intervienen en este campo en los Estado: Unidos, ha determinado que estos análisis incursionen dentro de un espectro más amplio y se detenga mucho más en la dinámica de esa "política burocrática"4. Por otra parte se ha señalado también que en el Reino Unido ha predominado un enfuquie histórico, basado en el estudio de casos frecuentemente compartimentalizados por períodos, mientras que en los Estados Unidos se ha desarrollado un enfoque más comparativo, basado en la elec-

FY. Dror, "Advanced Workshops in Policy Analysis for Senior Decision-Makers", documento preparado por el RIAL, noviembre de 1985.

${ }^{3 R}$. Klein, "Creating Problems", New Society, No 53, p. $14 \mathrm{I}$.

"S. Smith, "Foreign Policy Analysis", en el libro editado por él bajo el tftulo International Relations: British \& American Perspectives. 
çón de un conjunto de variables claves, y de un estudio del comportamiento de la política exterior de los distintos países en relación con cada una de ellas 5 .

Sin embargo, a nuestro juicio, en todas estas orientaciones existe un común denominador consistente en la tendencia o ofrecer una interpretación más descriptiva que analítica de la polftica exterior, ya sea en términos del número de actores que interviene en el proceso decisorio, ya sea en función de una visión. histórica o comparativa de lo que ha sido de hecho la politica exterior de los paises. Para fines no puramente académicos o ilustrativos, sino prácticos y operacionales, la formulación y aplicación de la política exterior a situaciones complejas, cambiantes y concretas, exige disponer de un marco conceptual más analítico.

Esta introducción no podría terminar sin decir algo acerca de qué debe entenderse por políticas (en este caso la política exterior) $y$ en qué consiste el análisis de ellas.

Bajo el término "políticas", se entiende un conjunto de áreas más o menos relacionadas entre sí. Tal vez su sentido más usual se refiera a los distintos campos de la actividad del Estado, pudiendo hablarse así de una política exterior, económica, industrial, monetaria o cambiara, sin distinguir mayormente entre la política como aspiración o como resultados de un programa. En otros casos se le da la connotación de expresar un propósito general, un estado deseable de cosas o un conjunto de proposiciones específicas destinadas a hacerlo realidad. Otras veces se alude a un programa, como un plan de ayuda externa bajo la forma de préstamos o el retiro programado de armamentos y tropas de una zona conflictiva. Con frecuencia se emplea esta palabra para indicar una línea de acción que ha sido objeto de una aprobación formal por parte de la autoridad respectiva. Conviene no confundir, como ocurre algunas veces y como se verá a continuación, el concepto de política con el de decisiones de la autoridad o el de resultados de un programa. Una politica incluye algo de los varios significados que se han mencionado aquí, como se subrayará más adelante, y constituye siempre un proceso que se desarrolla en el tiempo a través de varias etapas.

Al respecto también puede ser útil señalar lo que no es una política. Desde luego, como se ha dicho, no debe ser confundida con la decisión, que generalmente es más circunstancial y más estrecha y es adoptada dentro del marco más general de una política, como ocurrió con las decisiones de intervenir en Suez o de invadir las Islas Malvinas. Toda política involucra intenciones, sin reducirse a

'J. E. Anderson, Public Policy Making (Londres: Nelson, 1975). 
ellăs; pues incluye también el comportamiento inspirado por esas intenciones. Anderson la ha definido como "un curso de acción intencional seguido por un actor o un grupo de actores para abordar un problema o un área de interés" 6 . Sin embargo, dicho comportamiento puede involucrar acciones y omisiones. Al mismo tiempo, hay que tomar en cuenta que el propósito de una política puede ser definido retrospectivamente. Por otra parte, si bien toda política debe ser atribuida a una autoridad, o a una organización o un grupo, no hay que olvidar que en la práctica con mucha frecuencia intervienen en ella numerosas agencias, incluso ajenas a la organización - al grupo al cual se atribuye Ia política?.

Por "análisis de politicas" (no existe una traducción satisfactoria para el término inglés policy analysis, también se suelen entender diversas cosas. La más común se refiere al contenido de la misma: militar, cultural o de expansión de las exportaciones. Otros enfoques poren énfasis en sus resultados con el objeto de poder cuantificar sus costos. Otros más bien se refieren a estudios encaminados a evaluar ciertas políticas. $Y$ muchas veces su análisis se identifica con el proceso mediante el cual se argumenta en favor de ella o se defiende una política ${ }^{8}$.

En general, puede decirse que el análisis de la polftica exterior también es un proceso a través del cual se define el curso de acción más apropiađo para enfrentar una situación suficientemente general o recurrente como para requerir una pauta de conducta, y no ina decisión aislada con el objeto de lograr determinados valores, intereses $u$ objetivos. El análisis de toda política debe tener una serie de características, entre las cuales cabe mencionar su carácter aplicado, su contenido interdisciplinario, su sensibilidad frente a los imponderables que suelen hacer necesaria una polftica y su ca. rácter no desinteresado, es decir, su ptopósito de servir a un beneficiario.

Para los fines prácticos que persiguen estas notas, el proceso de formulación de la política y su análisis tienden a identificarse en la medida en que este último debe constituir el anticipo o el reflejo de ella. Por eso ya se ha señalado la indisoluble vinculación que existe entre el análisis, la planificación y la implementación de la polftica. En este próceso se han señalado etapas que, atendido el carácter preliminar de estas reflexiones, se sintetizarán en cuatro ni-

${ }^{\circ} \mathrm{G}$. T. Allison, Essence of Decision (Boston: Little \& Brown, 1971).

Tara una visión crltica, ver T. Dye, Understanding Public Policy, Prentice Hall, 1972).

sara un análisis pormenorizado de estas categorlas de análisis, ver B. W. Brown Hogwood y L. A. Gunn, Policy Analysis for the Real World (Oxford: Oxford University Press, 1984). 
veles principales: la definición del interés nacional o de la agenda internacional; la operacionalización de los intereses incluidos en la agenda; el establecimiento de objetivos y la identificación de cursos de acción alternativos; y los procesos a través de los cuales se adoptan las decisiones respectivas. Las cuatro secciones siguientes están dedicadas a cada uno de estos temas.

\section{El Interés Nacional y la Agenda Internacional}

El concepto de interés nacional se utiliza al mismo tiempo como un instrumento de análisis y como un componente de la política exterior. En la práctica, sin embargo, resulta mucho menos útil en el primero de estos roles, mientras que los estadistas parecen no poder prescindir de él en el segundo. Por lo tanto, aunque por su gereralidad el interés nacional ha dejado de ser útil como herramienta analítici en un mundo tan complejo, debido a su carga emocional y a que su propia generalidad permite justificar objetivos muy diversos, el concepto sigue orientando (o pretendiendo orientar) la política exterior ${ }^{9}$. Se olantea así la paradoja de que los analistas tienen que usar un concepto inadecuado para explicar las motivaciones y los obietivos de la política exterior, debido a la utilidad que posee su propia imprecisión, tratando de refinarlo, precisarlo y desagregarlo en la mejor forma posible, para acercarlo a los intereses reales due constituven la agenda internacional de un pafs en un momento determinado.

El concepto de interés nacional tiene una larga historia. Prefigurado durante la época del abcolutismo por "la voluntad del príncipe", los "intereses dinásticos" v la "razón de estado", conforme se consolidó la nación como expresión sociológica Y la democracia como forma política, aparecieron otros conceptos como "la voluntad general" $v$ el "interés público", antes de decantarse en la actual concepción de interés nacional. Sin embargo, si bien este concepto aparece en el discurso de los estadistas norteamericanos desde el establecimiento de la Constitución de los Estados Unidos. hubo que esperar hasta el siglo $\mathrm{xx}$ para que los analistas lo utilizaran sistemáticamente. Las conmociones creadas por las dos guerras mundiales al despertar el interés de las masas en la conducción de los asuntos internacionales, contribuyeron a hacer del interés nacional un concepto que podía ser usado para describir, explicar o evaluar la politica exterior de las naciones ${ }^{10}$.

Desde entonces el interés nacional ha sido "el perenne patrón de

'J. N. Rosenau, The Scientific Study of Foreign Policy (New York: The Free Press, 1971), p. 239 y siguientes.

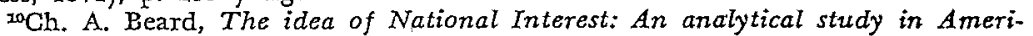
can Foreign Policy (New York: MCMillan 1934), p. 227. 
acuerdo con el cual la acción política debe ser juzgada y dirigida"'11. Morgenthau fue probablemente el fundador de una teoría realista de la política internacional fundada en el concepto del interés nacional. Según él los objetivos de la política exterior debían ser definidos a la luz de ese concepto12. Morgenthau reconocía que "los intereses que determinan la acción política en cada período histórico dependen del contexto político y cultural dentro del cual la polf́tica exterior es formulada"13. Sin embargo, en la práctica, en su análisis este autor descarta esos factores al definir el interés nacional exclusivamente en términos de poder: de hecho "los estadistas piensan y actúan en términos de intereses definidos como poder"14. Para Morgenthau el poder de que dispone una nación en comparación con otras es el factor que en última instancia asegura su supervivencia y el interés nacional, por sobre todo, consiste en mantener esos recursos o ese balance de poder. Esta visión sume al concepto en una irremediable ambigüedad que ha sido objeto de numerosas críticas.

La primera se refiere, precisamente, a la confusión entre el interés nacional y el poder. Este último es, evidentemente, un medio (Yr. para ser más precisos, uno de los medios) para alcanzar el interés nácional. La confusión del medio con el fin no sólo es lógicamente tautológica sino que también, en la práctica, oscurece la identificación de los intereses reales de una nación, al subordinarlos a un elemento instrumental como la acumulación de recursos de poder, exacerbando el nacionalismo en la política exterior y el conflicto en las relaciones internacionales.

Una segunda critica se refiere a que el concepto de interés nacional supone la existencia de una nación unívoca, homogénea y monolítica. Esto pudo ser cierto en la época anterior a la revolución francesa, cuya característica esencial "fue la identificación de la nación con la persona del soberano"15. La verdad, es que las sociedades nacionales son más heterogéneas de lo que esta presunción propone y que en el mundo moderno existe la tendencia hacia una creciente diversificación de la sociedad civil y del Estado, a través del surgimiento, la competencia y la articulación de múltiples grupos de interés organizados. Los realistas carecen de la inclinación a analizar los intereses reales que componen la agenda internacional

${ }_{H} \mathrm{H}$. Morgenthau. Politics among nations: the Struggle for Power and Peace (New York: Knopt, 2a ed., 1954), p. 9.

II Tbid, p. 528.

${ }^{2}$ Ibid, p. 8.

IIbid, p, 5. Ver también, del mismo autor, In Defense of the National Interest: A Critical Examination of American Foreign Policy (New York: Knopt, 1951). P. 242 .

${ }^{15}$ E. H. Carr, Nationalism and After (Londres: St. Martin, 1945), p. 2. 
de una nación y para hacerlo terminan por apoyarse en mecanismos procesales -las diversas formas que puede adoptar el proceso decisorio- eludiendo el definirlos en función de consideraciones sustantivas ${ }^{16}$. En último término esta visión conduce a un enfoque autoritario, subjetivo y acrítico. Como declaran dos destacados exponentes del pensamiento clásico "el interés nacional es lo que la nación, es decir, los que toman las decisiones en nombre de ella, deciden que es"'17.

Todo ello significa que, en tercer lugar, el interés nacional constituye un concepto "no operacional": no proporciona elementos de juicio para definir intereses específicos y para compararlos" o jerairquizarlos entre sí, como no sirve para desagregar la imagen de un interés nacional altamente abstracto. Tampoco sirve para agregar los múltiples intereses específicos de una sociedad en una agenda internacional susceptible de orientar la política externa del Estado.

Otra fuente de dificultades radica en el hecho de que en el mundo actual la integración internacional y las vinculaciones externas de las distintas sociedades nacionales se han expandido extraordinarianiente, dando lugar al surgimiento de múltiples intereses sectoriales, como se señalaba ya en la segunda de las consideraciones precedentes. Ello acentúa la inadecuación del concepto que estamos comentando para contribuir a la definición de esos intereses. Una de las expresiones de dicho fenómeno consiste en el progresivo desdibujamiento de la distinción tradicional entre política interna e internacional.

Por último, y sin intención de agotar las críticas formuladas frente a este concepto, cabe señalar que éste siempre ha sido usado en dos sentidos diferentes: primero, como un criterio para evaluar los intereses que están en juego en cada situación y las alternativas o cursos de acción más calíficados para preservarlos $y$, segundo, como una.justificación a decisiones ya tomadas. Es más, considerando su escasa utilidad- como herramienta analítica, el interés nacional es inyocado.con mucho más frecuencia para justificar retrospectivamente acciones ya cumplidas que para diseñar lo que debería ser es el futuro una política. Este uso del concepto está preñado de consecuencias negativas.

Debido a estas características, el concepto de interés nacional ejerce una influencia reduccionista en virtud de la cual todos los demás intereses de una nación se subordinan en última instancia a unos cuantos intereses irreductibles, que no son sino una versión nacional de la trilogfa individual "vida, libertad y propiedad", a

${ }^{18}$ J. N. Rosenau, op. cit., pp. 146-147.

${ }^{17 \mathrm{E}}$. S. Furniss Y R. C. Snyder, An Introduction to American Foreign Policy (N. Y.: Reinhart, 1955), p. 17, citado en Rosenau, op. cit. 
saber: la supervivencia física de la nación, la libertad de sus ciudadanos y su subsistencia económica. "En los Estados Unidos hubo un acuerdo sustancial durante muchos años después de la segunda guerra mundial en que esos tres valores fundamentales -o intereses nacionales irreductibles - debian modelar los propósitos y objetivos básicos de la política exterior de ese país"18. En un plano algo más concreto, pero por lo mismo más contradictorio, durante los años de post-guerra esos tres niveles de supervivencia se consideraron amenazados por dos riesgos principales: la expansión del comunismo internacional y el peligro de una tercera guerra mundial. Naturalmente, el temor a un nuevo holocausto frecuentemente inhibió a los Estados Unidos de emprender acciones encaminadas a contener a la Unión Soviética, lo que planteó la contradicción anteriormente señalada entre ambos objetivos $y$, por lo tanto, al interior del "interés nacional" tal como era entendido en esa época. De esta manera, el interés nacional demostró ser un concepto que se tornaba más ambiguo en la medida en que se diversificaran los valores y aumentaba la incertidumbre en la vida internacional.

Lo anterior implica que la falta de precisión de este concepto tiende a verse agravada por las distorsiones que suelen afectar la percepción que tiene un país acerca de la naturaleza de un sistema internacional caracterizado como anárquico -esto es, como constituido por el enfrentamiento entre diversos Estados orientados a perseguir sus respectivos intereses nacionales- ast como también acerca del interés nacional del adversario, distorsiones que se producen con tanta mayor facilidad cuanto más vagamente este concepto sea definido. Asl, como por ejemplo, la visión que tuvieron los Estados Unidos durante la post-guerra acerca de un mundo dividido por la guerra fría y de un adversario expansionista y agresivo, actuó como una especie de profecía autocumplida, frustrando muchas oportunidades para crear un orden internacional mucho más estable $y$ sembrando las semillas de la fragmentación y los conflictos que caracterizarian las relaciones internacionales a partir de los años 70 .

Las criticas anteriores pueden resumirse en la conclusión de que el interés nacional es un concepto no operacional, que no proporciona criterios para identificar intereses específicos, compararlos $y$ establecer una jerarquía entre ellos, para plantear opciones de politica, ni para evaluar los costos ni los beneficios de cada una de ellas. Como se ha anticipado, esta falla se ve exacerbada por la creciente complejidad del sistema internacional contemporáneo con su. proliferación de intereses contrapuestos y con un margen cada vez mayor de incertidumbre, agudizándose especialmente en tiem-

${ }^{28} \mathrm{Ver}$ el capítulo preparado con la colaboración de $\mathrm{R}$. O. Kehoane en el libro de A. George, Presidential Decision Making. The effective use of information and advice (Boulder: Westriew Press, 1980). 
pos de crisis. En esas circunstancias, lo más probable es que el interés nacional sea definido de acuerdo con los intereses del grupo gobernante o que incluso aquellos a quienes en un momento corresponde tomar las decisiones hagan depender esta definicióni de sus propios valores, particularmente si la decisión se toma bajjo la presión sicológica propia de una situación de incertidumbre o crisis. Por otra parte, y paradojalmente, "el hecho de que el interés nacional sea un objetivo no operacional estimula la tendencia, a que determinadas agencias o departamentos administrativos identifiquen las metas de la política exterior con sus propios intereses burocráticos, reemplazando una concepción más amplia y equilibrada de lo que exige el interés nacional", con lo que éste una vez mís se confunde con aquello que desean las personas que se encuentran a cargo del manejo de la situación en un momento determinado ${ }^{18}$.

Además de su ambigüedad y su carácter no operacional, el concepto de interés nacional tiene el defecto de excluir del análisis la posibilidad de emplear formas de diplomacia colectiva para resolver o regular determinadas situaciones o procesos, o formas multilaterales de limitación al uso de la fuerza, mecanismos acërca de los cuales hay interesantes experiencias en el periodo más reciente. Uno de los componentes de la visión actual de las relaciones internacionales radica en la percepción de la complejidad del mundo moderno, del avance del proceso de transnacionalización, de la interdependencia cada vez mayor entre las distintas sociedades nacionales, el creciente entrelazamiento entre los aspectos políticos, económicos y tecnológicos que presentan esas relaciones, y de la progresiva sectorialización y tecnificación de la política exterior. Dichas tendencias han dado lugar al surgimiento de una serie de.ámbitos, juegos o circuitos - políticos, ideológicos. religiosos, comerciales, financieros, tecnológicos, energéticos, militares o culturalesdotados de un alto grado de especificidad propia y definidos por un repertorio de intereses, actores $y$ regulaciones que les confieren cierta autonomía frente a las clásicas relaciones de poder entre las grandes potencias. Una de las maneras de capturar este fenómeno, apunta a la emergencia de diversos regímenes internacionales estructurados para pautar la interacción entre diversos actores nacionales y transnacionales dentro de cada uno de los circuitos anterjormente mencionados ${ }^{20}$. Estos regimenes representan ámbitos de articulación

${ }^{10}$ Ibid, p. 237.

${ }^{20}$ A. George, Presidential decision-making, op. cit. pp. 127 y 85. Ver también S. P. Krasner (ed.), International Regimes (Cornell U. P., 1983); M. Stewart, The Age of Interdependence Economic Policy in a Shrinking World (Cambridge, Mass.: MTT Press, 1984); R. O. Kehoane, After Hegemony: Cooperation and Discord in the World Political Economy (N. Y.: Princeton U. P., 1984) y J. G. Ruggie (ed.), The Antinomies of Interdependence (New York: Columbia U. P., 1988). 
de las políticas exteriores de los distintos países y de manejo colectivo de determinados problemas internacionales. El concepto del interés nacional no permite comprender estas experiencias ni proponer polfticas adecuadas para enfrentarlas.

Las críticas formuladas más arriba no deben hacernos perder de vista la importancia que vastos sectores polfticos, diplomáticos y analistas, continúan asignando al concepto de interés nacional. $\mathrm{Da}$ testimonio de ello la aparición en los Estados Unidos de una nuev:r revista publicada por Irving Kristol precisamente bajo ese nombre, en cuya primera edición se declara que sus supuestos consisten en "que el propósito primordial y abrumador de la política exterior norteamericana debe ser el de defender y promover el interés nacional de los Estados Unidos (un interés que engloba los valores y aspiraciones del pueblo americano así como también su seguridad frente a las amenazas externas y su bienestar material); que; para mal o para bien. la política internacional sigue siendo esencialmente una política de poder, y que lá eficacia de la capacidad militar en la conducción de la política exterior permanece inalterada; $y$ que la Unión Soviética constituye la principal amenaza importante para los intereses de los Estados Unidos y debe continuar siéndolo en el futuro previsib e'"2I. Nosotros, sin embargo, quisiéramos proponer un paso hacia adelante.

El concepto de agenda internacional nos parece promisorio en tal sentido ${ }^{22}$. Este concepto obedece a la percepción de que en un mundo cada vez más transnacional, más interdependiente y más complejo, en que proliferan los actores internacionales (gubernamentales y no gubernamentales), en parte porque las propias sociedades nacionales se desarrollan y diversifican generando múltiples grupos de interés que cada vez más frecuentemente buscan la satisfacción de sus aspiraciones en el frente externo, los intereses nacionales se vuelven mucho más sectorializados, desagregados y específicos- de tal manera que cada vez son menos susceptibles de ser englobados bajo el concepto abstracto del interés nacional- para constituir más bien una suerte de agenda internacional cuya elaboración pasa a representar una tarea central en la planificación de la política exterior. Tres rasgos han sido señalados, entre otros, como esenciales a la nueva agenda en torno a la cual se estructurará la competencia y la articulación internacional de los países: su carácter más diversificado, menos jerarquizado y más entrelazado que antes.

Mer nota de los editores en The National Interest, No 1, otoño de 1985.

${ }^{20}$ Entre los principales analistas de este concepto se cuentan $R$. O. Kehoane y J. S. Nye, especialmente en Power and Interdependence: World Politics in Transition (Boston: Little \& Brown, 1977). Ver también la introducción al libro editado por L. Tomassini, Transnacionalización y Desarrollo Nacional en América Latina (Buenos Aires: GEL, 1984). 
En efecto, a las tradicionales cuestiones geopolíticas, estratégicas y militares que monopolizaban la definición del interés nacional en el pasado, comienzan a ağregarse nuevos temas de interés vital para lás relaciones entre los Estados, como las relaciones económicas y comerciales, la competencia industrial y tecnológica, sus vinculaciones finaricieras, la energfa, el medio ambiente, el terrorismo, el narcotráfico y los nexos raciales, ideológicos y religiosos entre las distin'tás sociedades nàcionales.

Al mismo tiempo, el abrumador predominio de los asuntos relacionados con la seguridad estratégica de las naciones (identificadas, como hemos visto, con su ppropia supervivencia), cede paso a una percepción menos jerarquizada de los distintos intereses nacionales, que permite que unos $\mathrm{u}$ otros tomen la primacía dependiendo de los países, los sectores o los perfodos de tiempo involucrados.

Por último, no sólo se diversifican los intereses que persigue cada pars en sus relaciones exteriores sino que se multiplican también los canales de que cada sociedad nacional dispone para competir, cooperar o negociar en torno a esos intereses. Toda una variedad de actores gubernamentales y no gubernamentales, incluyendo la fragmentación del Estado en múltiples burocracias sectoriales que acompañan a los sectores privados en la persecución de sus intereses, (piénsese, en el caso de los Estados Unidos, en las posiciones contrapuestas de los Departamentos de Estado, de Defensa, de Comercio o del Tesoro, así como también entre las ramas del Ejecutivo y del Congreso, en relación con temas especificos que afectan de diversa manera a los distintos grupos de interés), multiplican también los canales de comunicación entre las diversas sociedades nacionales y facilitan el entrelazamiento entre los distintos temas.

Todos estos factores contribuyen a erosionar la capacidad - no ya analítica sino legitimadora $\longrightarrow$ del concepto de interés nacional en la formulación de la política exterior y atribuye nueva importancia a Ia confección de la agenda internacional y a los mecanismos que intervienen en dicho proceso. Asimismo la capacidad de que disporen determinados organismos o sectores para vincular unos temas con otros en el curso de sus negociaciones y para lograr transacciones y compensaciones, se convierte en una fuente particular de poder en el plano de las relaciones internacionales (de ahr la expresión inglesa. "Iinkage politics"). Uno de los aspectos abordados en la próxima sección se refiere, precisamente, a las distintas instancias a través de las cuales se define la agenda internacional de los parses.

\section{La operacionalización de los intereses nacionales}

un conjunto de intereses que responden en buena medida a la forLa agenda internacional, tal como se describe más arriba, incluye 
ma como está divida la sociedad y el Estado, susceptibles de ser identificados con relativa claridad, jerarquizados, articulados o compensados, como ocurre cuando algunos de ellos tiene que ser total o parcialmente sacrificado para satisfacer otros de mayor importancia. El interés nacional, por la excesiva generalidad de este concepto, su ambigüedad y sus tautologias (como las de identificarlo con los medios empleados para alcanzarlo -el poder-o con las preferencias de la autoridad que lo proclama), no podfa ser claramente definido, y no proporcionaba un instrumento analítico para optar entre alternativas de políticas, si bien muchas veces sirvió para justificarlas una vez adoptadas. La agenda internacional, en cambio, constituye un repertorio de intereses o temas más precisos y susceptibles de ser operacionalizados.

Dicho proceso incluye una serie de funciones que se podrían englobar en tres categorías: el establecimiento de la agenda, la fijación de los objetivos y la determinación de los cursos alternativos de acción apropiados para alcanzarlos ${ }^{23}$. Esta sección se refiere a la primera de ellas.

El establecimiento de la agenda incluye la identificación de los temas "que podrían integrarla, la selección de los más relevantes y la definición de los mismos.

El primer paso en el proceso de análisis de la política exterior consiste en identificar los principales problemas y oportunidades que enfrenta un país en las distintas áreas en que se desenvuelven sus relaciones externas. Todos los gobiernos disponen de mecanismos formales o informales para hacerlo. Estos temas pueden ser periódicos (los presupuestos anuales de defensa), recurrentes (la aplicación por parte de terceros de medidas proteccionistas contra los productos de exportación más competitivos) o emergentes (una guerra o una oferta de inversiones externas no previstas). Se ha señalado que para que un tema adquiera relevancia generalmente se requiere que haya alcanzado una situación de crisis o al menos una marcada particularidad, ejerza un impacto suficientemente generalizado, tenga connotaciones emocionales o simplemente esté de mo$\mathrm{da}^{24}$. Naturalmente, los sectores que intervienen en la identificación de estos temas varian grandemente, yendo desde la opinión pública ilustrada (como en el caso de un conflicto limítrofe), hasta círculos muy especializados (como en la política científica y tecnológica internacional o en la política de defensa). Pero este último aspecto se examinará en la sección siguiente.

Lo anterior plantea la conveniencia de encontrar sistemas más

Este esquema está tomado de B. W. Hogwood y L. A. Gunn, Policy Analysis for the R'eal World (Oxford: Oxford U. P., 1984), caps. 5, 6 y 7.

stoid., p. 68. 
activos para la identificación de estos temas. El mejor período para hacerlo es antes que den lugar a una crisis. Además, una vez planteados, los arreglos institucionales necesarios para enfrentarlos toman bastante tiempo. Por otra parte, y si la decisión es adoptada en plena crisis, hay mayores probabilidades de que resulte equivocada. Por cierto existen formidables obstáculos que dificultan un proceso de identificación de cuestiones internacionales más activo. Por un lado está la tentación de los gobiernos de concentrarse en la coyuntura, fortalecida por la inclinación de los políticos y burócratas de mayor importancia a privilegiar los temas que pueden influir hoy en su carrera, todo lo cual crea una brecha entre lo que es objetivamente racional y lo que es racional para un gobierno o para un dirigente en un momento dado, desde el punto de vista de su estabilidad y su suceso. Una dificultad todavía más estructural radica en el desigual acceso que tienen los distintos sectores a las instancias que deciden qué temas integrarán la agenda; este desequilibrio determina que aquellos que Io tienen en mayor medida impongan sus intereses, su visión o sus preferencias sobre ella. La rotación frecuente de las burocracias involucradas en este proceso y la excesiva concentración de responsabilidades sobre los eslabones más influyentes, lúcidos o eficientes de la cadena burocrática, que son precisamente los que deberían anticipar y escoger los temas, obstruyen también este proceso. Por último, resulta difícil desarrollar métodos que permitan interpretar y procesar señales demasiado novedosas, atípicas o débiles, o incluso, la ausencia de mensajes. Como dijo Holmes a Watson en un caso determinado, el hecho de que el perro no ladrara durante la noche le proporcionó la clave para descubrir la identidad del intruso.

No hay aquí espacio para señalar los principales métodos que pueden emplearse en el proceso de identificación de temas. Pero no podríamos dejar de hacer referencia a una discusión que se repite con frecuencia: si se debe asignar esta función, y por extensión la de sentar las bases de la planificación de la política exterior, a una unidad especializada o a los diversos departamentos de un servicio exterior y de los demás organismos vinculados con las relaciones externas de un país determinado. Esta última y más tradicional opción tiene desventajas, ya que no siempre hay manera de asegurar que estos departamentos, además de cumplir sus tareas rutinarias, estén atentos a la identificación de nuevos temas; también está el peligro de que privilegien aquellos que coinciden con los intereses del departamento; asimismo resulta difícil integrar la visión sectorial de cada uno de ellos; por último, no todos los departamentos logran hacerse escuchar en los escalones decisorios más altos. Pero también hay desventajas en el establecimiento de una unidad encargada de cumplir esta función en forma centralizada: no sólo se 
pierde contacto con los problemas reales que tienen los departamentos, sino que frecuentemente se crean resistencias dentro de ellos que impiden la aceptación de las conclusiones alcanzadas, se reduce la responsabilidad del personal superior en este campo y se estimula el peligro de que los problemas sean planteados desde una perspectiva más estrecha, impuesta por la composición del correspondiente mecanismo burocrático y por el espíritu de cuerpo que se crea en ellos. Probablemente los más apropiados sean sistemas mixtos, de los cuales por cierto se han ensayado varios, pero este es un tema que debería reservarse también para la sección siguiente.

La segunda función de este proceso consiste en la jerarquización de los temas identificados como relevantes y la selección de los que deben ser incluidos en la agenda. Hay aquí varias opciones administrativas que se examinarán más adelante. En general ellas se escalonan entre fórmulas organizativas y otras más intuitivas o políticas. Un especialista, al concluir un acucioso estudio, encuentra que "la mayor parte de las decisiones acerca de qué temas deben ser objeto de una planificación detallada se basan en criterios esencialmente políticos que con frecuencia no se apoyan en ningún análisis sistemático de la situación"25. Por eso, nunca está de más reiterar que tarde o temprano es necesario tomar una decisión acerca de las estructuras institucionales más adecuadas para cumplir la función de identificar y seleccionar los temas que deben formar parte de la agenda internacional.

Pero junto a la cuestión institucional se plantea la de los criterios que deberían ser empleados para seleccionar estos temas. Uno de los autores que hemos seguido más de cerca en esta parte los agrupan en cuatro categorías ${ }^{26}$. Los primeros tienen que ver con el contexto en que se plantea la situación: aquí se incluyen preguntas acerca de si hay tiempo para el análisis; sobre el grado en que el problema puede tener consecuencias políticas y la naturaleza de esas consecuencias; si ya se han adoptado posiciones relativamente rígidas acerca del problema, y sobre cuán central es éste desde el punto de vista de un servicio exterior y sus políticas. El segundo grupo de criterios se refiere a las características internas del problema: aquí se plantean varias preguntas acerca de que si existe un margen de opción; sobre el grado de consenso existente en torno a la definición del problema y sus posibles soluciones; acerca de su complejidad; sobre el grado de incertidumbre que lo rodea; sobre la medida en que tiene connotaciones valorativas, y sobre cómo lo ven y qué importancia le asignan los interlocutores o adversarios del país respectivo. El tercer grupo tiene relación con las repercusiones

${ }^{25} \mathrm{C}$. Wiseman, "Selection of Niajor Planning Issues", Policy Sciences, número 9,1978 .

${ }^{\approx}$ Hogwood y Sunn, op. cit., pp. 92 y siguientes. 
del problema: con la escala o magnitud de sus consecuencias; en el número de actores afectados; por el poder relativo de los mismos; con la profundidad en que son afectados esos actores; con la probabilidad de que las consecuencias del problema puedan afectar la forma en que se plantean otros temas, y con la forma en que el gobierno pueda salir fortalecido o debilitado frente a otros países al abordar ese problema. La última categoría de preguntas se refiere a los costos de encararlo: su monto, en términos materiales y políticos; el periodo durante el cual podría ser necesario pagarlos; la probabilidad de que limiten la capacidad de ese gobierno para atender otros problemas, etc.

Estos criterios u otros similares deberían ser utilizados como un listado mental de aspectos que es conveniente tener en cuenta en forma más o menos sistemática para ponderar la importancia de los distintos temas. Cuán sistemático sea el procedimiento que se emplee para aplicar esos criterjos, es una cuestión tan fundamental como el contenido de la lista anteriormente mencionada. En todo caso parece conveniente buscar procedimientos más racionales e institucionalizados que los de dar tiempo al asunto, llevarlo al gábinete del ministro o transferirlo a otras agencias sin mayor análisis, métodos que muchas veces se emplean en la práctica.

El análisis y la planificación de la política exterior. comienzan con la operacionalización de la agenda internacional, y este proceso a su vez se inicia con la identificación y selección de los temas que deben integrarla, pero una vez cumplidas estas tareas aún falta definir con precisión los temas. Debemos advertir que el uso de la pa labra temas (imperfecto equivalente del vocablo "issue") es preferibIe y más amplio que otras palabras similares, porque un tema puede envolver problemas al igual que oportunidades. Hecha esta advertencia, recordemos que la identificación de los distintos temas se basa en una percepción o conciencia inicial, refinada por la aplicación de algunos criterios para jerarquizar la importancia de cada uno de ellos, lo cual aún no equivale a la definición del tema. Por ésta queremos significar "el proceso mediante el cual un tema (problema, oportunidad o tendencia), habiendo sido reconocido como tal y colocado en la agenda a que se refiere una política, es percibido por las distintas partes interesadas; es explorado con mayor detalle, articulado y, en la medida de lo posible, cuantificado; y, en algunos si no en todos los casos, es materia de una definición autorizada o por lo menos provisionalmente aceptable en términos de sus posibles causas, componentes y consecuencias" ${ }^{\prime \prime}$.

La definición del tema es importante porque, como hemos visto, en Ja práctica su identificación está fuertemente basada en la intui-

rlbid, p. 108. 
ción, en Ia influencia de determinados grupos de poder y en la acción política. Ello suele conducir, en las primeras etapas señaladas hasta ahora, a serios errores de percepción acerca de la naturaleza, importancia y posibles consecuencias de un problema. Como lo han señalado otros autores, "una definición plausible pero incompleta a un problema puede ser más peligrosa que una definición equivoca$\mathrm{da}^{\prime \prime}$ ( $\mathrm{y}$, agregaríamos nosotros, que la completa falta de percepción del mismo) ${ }^{28}$. Así, por ejemplo, muchos observadores estiman que para Argentina habría sido mejor desconocer o restar importancia al problema de Malvinas, que definirlo en términos tan equivocados como los que condujeron al curso de acción que adoptó esa guerra.

La definición de un tema también incluye ciertas fases. La primera se refiere a la forma como el tema es "percibido". La segunda tiende a refinar esa percepción explicitando las motivaciones emocionales o políticas que subyacen tras ella, relacionándola con otros factores presentes en nuestro "mapa cognitivo", o estableciendo ]as concatenaciones o superposiciones del tema con otros conexos. Una tercera fase consiste en agregar a las percepciones oficiales, provenientes de las agencias formalmente autorizadas para manejar el tema, las de otros actores involucrados en el mismo para llegar a una visión más amplia, multidimensional y equilibrada. Una cuarta fase consiste en cuantificar las dimensiones del problema en el contexto de la política exterior del país de que se trate. Una más, consiste en reconocer la influencia que las instancias de poder tienen en la definición del tema y en precisar el grado y la dirección en que esa influencia puede distorsionar la definición del mismo.

Aquf también se podría confeccionar mentalmente un listado de los principales aspectos que deberían ser considerados en la definición de cada tema. ¿Quién plantea la existencia del problema? ¿Se trata de un problema real o imaginario? ¿Qué grado de consenso so puede esperar en torno a su naturaleza y soluciones? ¿Existen antecedentes o es demasiado pronto para definirlo? Si ya está definido ¿dentro de qué marco icleológico o de intereses se hizo? ¿Cómo es definido el tema por los demás actores internacionales? ¿Cuáles son. los marcos de referencia o las visiones de los demás actores involutcrados? ¿Hasta qué punto se le puede comprender en forma aislada o conectándolo con otras cuestiones? ¿Cuál es la cadena causal que plantea el problema? ¿Guáles son sus posibles consecuencias?

\section{La determinación de los objetivos y opciones}

La operacionalización de los intereses nacionales - la identificación, selección y definición de los intereses específicos que componen la I980).

${ }^{29}$ A. M. Steiss y G. A. Daneke, Performance Administration (Lexington Books, 
agenda internacional de un país determinado- es lo que permite establecer los objetivos, prioridades y opciones que enfrenta un país en las distintas áreas por las que discurre su accionar externo. La inclusión de un tema en dicha agenda, y la correcta definición de sus alcances, es condición necesaria para que la política exterior de un país fije sus objetivos en relación con este tema. El establecimiento de objetivos específicos ocupa un papel central en la formulación y aplicación de una política. Una parte de la literatura sobre el tema distingue entre el papel de los objetivos en las tareas de administración y el papel de los mismos en.la dinámica de las organizaciones.

Dos tendencias o enfoques principales han predominado en el análisis de las funciones que cumple la administración en relación con el establecimiento de objetivos.

El enfoque racional presume que los encargados de tomar las decisiones tienen un alto grado de control sobre las circunstancias, $\dot{y}$ que deben desarrollar una conducta activa y manipulatoria, particularmente en relación con el establecimiento de sus objetivos. Éstos permiten definir con gran precisión los cursos de acción más adecuados para alcanzarlos, sus costos y los recursos necesarios para impulsarlos. También permiten evaluar los resultados en función de los objetivos perseguidos ${ }^{29}$.

Este enfoque contrasta con la tradición incrementalista, según la cual los que toman las decisiones tienen poco control sobre las situaciones y disponen de una capacidad de opción muy limitada. Para ellos la formulación de la polf́tica es más reactiva que activa y sus programas deben ser reexaminados constantemente a la luz de la experiencia más que a la luz de los objetivos iniciales. Es más, según ellos, las organizaciones y programas carecen de objetivos, y sólo deben evaluarse en función de sus resultados: son los individuos y los grupos los que fijan las metas. De acuerdo con esto, toda política podría ser evaluada en forma diferente según el grupo que esté en el poder en el momento de examinarla retrospectivamente. Aquí la recomendación apunta a que una política sea lo suficientemente flexible y bien informada como para responder a la evolución de la situación a la que se refiere, antes que lo suficientemente racional y rigurosa como para asegurar el cumplimiento de determinados objetivos como originalmente se previeron. La mala ejecución de una política es mucho peor que la insuficiente precisión en el establecimiento de estos últimos ${ }^{30}$.

${ }^{2}$ Ver R. Albanese, Management: Towards Accountability for Performance (Irwin: 1975) y también E. F. Harrison, The Managerial Decision-Making Process.

${ }^{30} \mathrm{C}$. E. Lindblom, The Intelligence of Democracy (New York: Free Press, 1965) y The Policy Making Process (Prentice Hall, 1968). 
Guando se pasa de la fijación de los objetivos en la ejecución de una política -en forma más racional o más incrementalista- al papel de dichos objetivos en una organización burocrática, el tema se vuelve problemático. El análisis de las burocracias -como los servicios exteriores y las demás agencias vinculadas con ellos- desdibuja el papel de los objetivos que resaltaba tan claramente al analizar una política. Es más fácil establecer los objetivos de éstas que los de una organización burocrática. Ya se ha dicho que, según algunos, no son las organizaciones sino las personas que las dirigen las que realmente tienen objetivos. Como las burocracias son por definición compartimentalizadas y complejas, lo normal es comproborar que persiguen objetivos múltiples, y con frecuencia contradictorios. Al mismo tiempo, el comportamiento cotidiano de una buracracia permite apreciar crecientes brechas entre los objetivos declarados y los reales. Por último, es normal que los objetivos de una organización además de ser múltiples y contradictorios, cambien constantemente a lo largo del tiempo.

Aunque la importancia de los objetivos en el análisis de la política exterior puede ser exagerado, particularmente en la medida en que el enfoque sea más racionalista, el énfasis en los problemas que presenta el proceso de fijación de dichos objetivos implica a veces un escepticismo extremo. Por otra parte, una visión de Jas organizaciones burocráticas como entidades sin objetivos institucionales y cuyos miembros carecen de todo sentido o de propósito colectivo, parece ser una descripción exageradamente negativa. También aquí conviene llegar a un equilibrio entre las visiones más pesimistas y más optimistas sobre el tema. EI establecimiento de objetivos estrechamente relacionados con los intereses incluidos en la agenda internacional de un país, es una condición necesaria para la formulación y la adecuada implementación de una política, así como también para que las organizaciones burocráticas encargadas de planificarla y de llevarla a cabo, puedan desempeñar sus tareas en forma moderamente racional. Con todo, conviene liberar la función de fijar los objetivos de la política exterior de las expectativas depositadas en este proceso por los enfoques más prescriptivos y racionalistas para apoyarse, en una medida apreciable, en aproximaciones más tentativas e incrementalistas.

Debido a que la agenda internacional de cada país es compleja y heterogénea, su política exterior debe perseguir con frecuencia objetivos múltiples y contradictorios. En estos casos, la tarea del analista y planificador de la política exterior consiste en definir sus prioridades de conformidad con técnicas similares a las mencionadas en otras de este ensayo y que no vale la pena volver a señalar aquí.

Pero tal vez su tarea más importante desde un punto de vista práctico, una vez fijados esos objetivos, consista en determinar las 
opciones disponibles desde el punto de vista del curso de acción que se debe seguir. La elección de uno de ellos, entre distintas alternativas, forma parte central del proceso de análisis y planificación de la política exterior.

De hecho existen dos aproximaciones básicas a este proceso. La primera consiste en identificar las opciones disponibles a través de un método predominante pasivo o reactivo, consistente en buscar básicamente esas opciones entre aquellas que ya hayan sido propuestas o ensayadas por el gobierno, el servicio exterior u otras agencias. Esta aproximación se basa en la tendencia a creer que el rango de opciones abierto a los que formulan la politica es generalmente muy estrecho, que las más seguras desde el punto de vista de sus resultados son aquéllas que ya han sido ensayadas y que cuentan cos el respaldo de la "sabiduría convencional", y que innovar siguiendo cursos de acción antes nunca explorados es particularmente peligroso en el campo de la política exterior. El otro enfoque consiste en "generar opciones considerando conjuntamente las antiguas y las nuevas, con el fin de que la elección se haga sobre la base de un espectro más amplio de posibilidades"31. Aquí parece haber consenso en que, tratándose de generar opciones nuevas, la racionalidad juega un papel limitado, y es necesario apelar a la imaginación incorporando al proceso de análisis a personas que dispongan de una buena cuota de ella, confrontando las ideas de distintas personas en un ejercicio colectivo (brain storming), buscando inspiración en la conducta de otras naciones, de otras agencias dentro del Estado, 0 en las lecciones de la historia ${ }^{32}$.

Al igual que en los niveles de análisis anteriormente mencionados, también se podrían confeccionar listas mentales de aspectos que deberían ser considerados en la identificación y elección de opciones. Así, por ejemplo, a manera de punto de partida deberían precisarse los temas o intereses que se encuentran en juego; a continuación, determinar los objetivos más compatibles con esos intereses o, mejor aún, más conducentes a darles cumplimiento; en seguida se deben definir todas las opciones abiertas con respecto a los cursos de acción más apropiados para lograr esos objetivos. Hecho esto, se deberían estimar los costos involucrados en cada acción en comparación con los beneficios esperados. También debería anticiparse la reacción de los interlocutores o adversarios frente a cada una de las opciones disponibles y el margen de incertidumbre que

sVer H. A. Simon, Administrative Behaviour, 3a edición, 1976, y también Y. Dior: Public Policy Making Reexamined (Chandler, 1968).

${ }^{32}$ Sobre Ios usos de la historia, ver G. A. Craig $y$ A. L. George, Force and Stalecraft: Diplomatic Problems of our time (Oxford: Oxford U. P., 1983) asf como tambien R. E. Newstadt y E. R. May, Thinking in Time: The Uses of Eristory for Decision-Makers (New York: Free Press, 1986). 
rodea a cada una de ellas desde el punto de vista de su viabilidad - de la seguridad de obtener los resultados deseados. Las consecuencias directas o indirectas de las distintas opciones, tanto para el país que está aplicando una política como desde el punto de vista de la reacción de otros actores, constituye otro aspecto que se debería considerar en este proceso. Con estos aspectos y otros similares a la vista, se pueden determinar cuáles de las opciones disponibles son las más aptas para maximizar el cumplimiento de los objetivos previamente establecidos.

Se han desarrollado numerosas técnicas para la adopción de decisiones en relación con la selección de opciones adecuadas. En este ensayo preliminar sólo cabe mencionar, a título de información, algunas como la programación lineal, la programación dinámica, el uso de matrices costo-beneficio y el de esquemas centrados en torno al diseño de un "árbol de decisiones", junto con otras relacionadas con la apreciación de los aspectos financieros y presupuestarios de ia elección de opciones, incluyendo técnicas encaminadas al control de los resultados de la decisión a través de su costo presupuestario ${ }^{33}$.

\section{El proceso de adopción de decisiones}

El proceso de adopción de decisiones es, en definitiva, aquél durante el cual se construye la agenda internacional que en la práctica va a concitar la atención de la política exterior de un país, se van a operacionalizar los temas o intereses incorporados a la agenda y se van a determinar los objetivos y opciones de la política exterior. $\mathrm{Su}$ importancia no puede ser mayor. Incluso, dado el lugar que ocupa como una disciplina semiautónoma en el campo de los estudios internacionales y del estudio de políticas (policy science), desborda considerablemente las limitaciones de este ensayo y será tratado en forma todavía más sumaria.

Con todo, como se había advertido en un comienzo, no conviene confundir cada una de las etapas anteriores con el proceso de adopción de decisiones ni reducirlas solamente a este último: en los demás hay un alto componente analítico, según el cual el analista debe elegir constantemente por medio de decisiones conceptuales, que forman una especie de continuo con aquéllas de carácter político mediante las cuales se adopta un curso específico de acción.

Conviene señalar desde el comienzo, el conflicto que con frecuencia se plantea entre la calidad de la decisión y su viabilidad. Esta última depende, fundamentalmente, de tres cosas. En primer lugar, de que la decisión cuente con un nivel mínimo de apoyo. Las más esclarecidas decisiones se frustran por falta de consenso: a esto se

${ }^{5}$ Hogwood y Gunn, op. cit., pp. 177 y siguientes. 
refiere el grueso de esta sección destinada a analizar el proceso de adopción de decisiones. Una segunda dificultad deriva de la relación entre la calidad de decisión y el tiempo requerido para adoptarla y/o para llevarla a calo: ese período, si es muy dilatado, puede comprometer sus resultados. Otro factor que atenta contra la viabilidad de unạ decisión consiste en la magnitud de los recursos necesarios para implementarla. Por eso, los que toman las decisiones con frecuencia tienen que entrar en compromisos entre la calidad de la decisión, por una parte, y su grado de consenso, el tiempo necesario para llevarla a cabo y los recursos requeridos para su implementación.

Estos tres aspectos condicionan el elemento central en que depende la calidad de acción: la identificación adecuada de los intereses en conflicto y su operacionalización en términos de objetivos y de opciones. "Una decisión de alta calidad es aquélla en que el Presidente (u otros funcionarios de nivel político) pondera correctaruente el interés naciona! en una situación particular y escoge la política u opción que más probablemente conducirán a satisfacerlo con un costo y riesgos aceptable:"34. Ya se ha explicado como el concepto de interés nacional, que en esta definición sin duda se usa como un signo taquigráfico para expresar una gama de intereses más compleja, debe desagregarse en un conjunto de temas susceptibles de configurar una agenda internacional más amplia y realista.

Casi todas las listas mentales de criterios que deben ser tomadas en cuenta en las distintas etapas del proce-o de análisis de la política exterior se aplican al proceso decisorio. Entre estos cabe destacar, resumiendo y enfatizando algunos de los criterips anteriormente mencionados, la neces:dad de disponer del espectro más amplio posible de información a fin de poder efectuar un diagnóstico adecuado del problema; de basarse en una evaluación y definición correcta del mismo; de tomar en cuenta todos los otros aspectos con los cuales éste está relacionado; de establecer con claridad los objetivos que deben perseguirse para resolver el problema, y considerar y jerarquizar todas las opciones que se abren desde un punto de vista operativo; de anticipar cuidadosamente las dificultades que pueden obstaculizar la implementación de la política $y$, sobre todo, la reacción de los demás actores.

Se ha señalado que generalmente existen, con muy diferentes énfasis en el papel desempeñado por cada uno de ellos, tres subsistemas en el proceso decisorio: individual, de grupo e institucional. No sólo es interesante destacar la naturaleza, características y pautas de funcionamiento de cada una de estas esferas, sino que también analizar las relaciones que suelen darse entre ellas: la psicología in-

34. L. George, op. cit., p. 3. 
dividual, la dinámica de grupo y las pautas que imperan en una organización compleja. También es interesante anticipar de qué mànera cada una de ellas se complementa o entra en contradicción con las demás frente a factores propios del sistema internacional contemporáneo que tornan más difícil el proceso decisorio, tales como la complejidad de dicho sistema, la creciente dispersión de los valores $e$ intereses nacionales, y la incertidumbre cognitiva.

La primera de estas esferas se refiere a los personeros que participan a título individual en adopción de decisiones. Desde diversos ángulos se ha subrayado en la literatura relativa a este problema los modos en que la personalidad, la experiencia o la formación de estos individuos influyen en la forma en que éstos perciben el problema y se inclinan a adoptar determinadas líneas de conducta frente al mis$\mathrm{mo}^{35}$. Aquí la tipología se extiende a través de tres polos principales: los factores pasivos (que prefieren que las situaciones se resuelvan por sí mismas), los que tratan de definirlas o resolverlas a partir de paradigmas preestablecidos y los que se inclinan a utilizar y evaluar toda la información de que pueden disponer para fundamentar -y modificar si es necesario- su diagnóstico de la situación y sus posibles soluciones. Estas diferencias, en la medida en que el factor individual influya en la política exterior, determinan las distincio. nes observables entre aquéllos que se limitan a reaccionar frente a los acontecimientos, los que se basan es las imágenes o los clichés que tienen acerca de la situación, y los que se esfuerzan por adaptarse efectiva y permanentemente a las cambiantes características del mundo real ${ }^{36}$. El primer tipo de personajes es una especie de fatalista histórico, el segundo un maximizador de consistencia conceptual o ideológica, y el tercero un solucionador de problemas. Esta última actitud supone dejar detrás la comodidad de descansar en el paso del tiempo y la intervención de otras circunstancias para resolver los problemas, así como también los prejuicios, preferencias y estrechez de miras del que repite pautas y experiencias previas.

Una sugerencia interesante desde el punto de vista práctico es la que considera que la cantidad de información no tomada en cuenta es Io que define una actitud pasiva, prejuiciada o analítica: la prihera evita involuntaria o deliberadamente procesar nueva información; la segunda la emplea selectivamente para confirmar imágenes preestablecidas; mientras que la tercera centra la mayor parte de su atención en ella, la evalúa permanentemente y está siempre dispuesta a revisar conclusiones anteriores a la luz de nuevas evidencias. Tal vez Ia actitud más corriente en la diplomacia convencional es la intermedia. Se han dado múltiples ejemplos de decisiones en donde la información que iba llegando a los responsables de adoptarlas fue

sibid, pp. 61 y siguientes.

soIbid., Cap. III. 
utilizada para confirmar profecías, expectativas o temores previos a través de un proceso mental que los norteamericanos llaman "wishful thinkinq". El optimismo de las grandes potencias con respecto a su posibilidad de controlar la situación en Suez y el pesimismo norteamericano con respecto a la repetición de otras Cubas, el cual determinó la intervenión en la República Dominicana, han sido citados por diversos autores en este sentido ${ }^{37}$.

Particularmente importante en este campo resulta la imagen que un país tiene sobre la posición de sus interlocutores o adversarios. Aquí es donde con mayor frecuencia enraizan los clichés basados en nociones préestablecidas o en experiencias previas con grave detrimento para la adecuación y flexibilidad de una política. Así, por ejemplo, la política de los Estados Unidos durante la guerra fría estuvo jalonada de visiones distorsionadas acerca de las supuestas -y contradictorias- posiciones de agresividad o de debilidad șoviéticas. Por eso los norteamericanos fueron sorprendidos por la aceptación soviética al plan Baruch, al armisticio coreano, a la conferencia de Berlín de 1954, al tratado austríaco y a la cumbre de Ginebra de 1960.

La segunda instancia que normalmente forma parte de los procesos de decisión, con mayor o menor peso, es colectiva; se refiere a los grupos asesores de los que deben tomar las decisiones. Desde los consejeros de los príncipes hasta los modernos grupos consultivos, esta práctica ha tenido numerosas expresiones en la historia ${ }^{38}$. No obstante los numerosos análisis realizados acerca de las formas y roles que pueden adoptar estos grupos, todavía distamos mucho de comprender adecuadamente sus funciones, posibilidades y limitaciones.

Existe un amplio margen de opiniones acerca de los objetivos que debería perseguir la asesoría: satisfacer necesidades cognitivas que deben ser llenadas antes de adoptar la decisión; asegurar la obtención de un consenso lo más amplio posible; legitimar la decisión una vez tomada, o diluir el stress generado por el proceso de adopción de decisioneś, particularmente en una situación de crisis, compartiendo la responsabilidad en una instancia real o aparentemente colegiada. Se han señalado también muchos factores que pueden anular esas ventajas: las tensiones, la falta de imaginación o la rutina que puede producir el hecho de trabajar permanentemente juntos; el estrechamiento del ángulo de visión y de los márgenes de opciones que produce el hecho de confrontar constantemente distintos puntos de vista, generar convergencias y habituarse a encon-

TVer. A. Lowenthal, The Dominican Intervention (Cambridge, Mass.: Harvard U. P., 1972), p. 154, sobre la repetición de "otras Cubas", y también R. Jazvitz, Perception and Misperception in International Politics (N. Y.: Princeton U. P., 1976), cap. 4.

${ }^{3 R} \mathrm{H}$. Goldhamer, The Advisor (N. X.: Elgenier, 1987). 
trar áreas de consenso o mínimos comunes denominadores, y las distorsiones que afectan al proceso de decisión cuando éste se apoya en grupos colegiados en una atmósfera de presión psicológica generada por una situación de crisis ${ }^{39}$. También se han señalado los peligros que enfrentan los grupos colegiados, al cifrar demasiadas expectativas en ese mecanismo, perdiendo contacto con los niveles tanto políticos como técnicos que tienen responsabilidad en la cima y en la base por la adopción de decisiones y prestando más atención a la opinión del grupo que a la cambiante información que sería posible considerar en un momento determinado. En general, se han subrayado los peligros de que el grupo quede absorbido por la jerarquización, la centralización y el ritualismo de la instancia colectiva.

Se ha procurado también identificar las condiciones y alternativas bajo las cuales los grupos asesores colegiados pueden cumplir más eficazmente sus funciones. Entre éstos se mencionan el tamaño del grupo, la composición de sus miembros, la jerarquía establecida entre ellos, la diferenciación de sus distintos roles, la cohesión entre sus miembros, la naturaleza y amplitud de las tareas encomendadas a ellos, las pautas adoptadas por el grupo para desempeñar su trabajo, los estilos empleados para administrarlo y la naturaleza del liderazgo desarrollado dentro de ellos ${ }^{40}$. Incluso en el plano de la conducta de sus miembros se han mencionado, como factores que contribuyen a su menor o mayor eficacia, la frecuencia de sus intervenciones, el nivel que ocupan en el rango de prestigio, su base de representación, las ventajas y desventajas de una actitud más activa - más pasiva, y los beneficios de la moderación. Entre las funciones que dentro de estas condiciones. pueden cumplir los grupos asesores, se mencionan la posibilidad de ampliar la información y las opciones que se manejan en una situación determinada, su capacidad para estimar desde un punto de vista pluralista los riesgos y oportunidades encerrados en ella, su potencialidad para generar concenso y su papel morigerador frente a la influencia abrumadora de una autoridad personalista o elitista. Todo ello debería redundar en la reducción de la incertidumbre en el proceso decisorio ${ }^{41}$.

En suma, las ventajas y desventajas de la asesoría colectiva frente a la competencia individual en el proceso de adopción de decisiones y sus funciones principales - solución de problemas y cálculo de riesgos- han sido ampliamente discutidos. Las principales fuentes de presiones que podrían limitar la autoridad de estos grupos radi-

${ }^{3} \mathrm{~A}$. L. Janis, Victims of Group Thinking (Boston, 1972).

"R. F. Bates, "Interaction Process Analysis", Reading, 1950.

"Dos libros fundamentales para analizar estos aspectos son los de J. G. March y H. A. Simon, Organizations (New York: Wiley, 1958, y de A. Dawns, Inside Bureaucracy. 
can en la tendencia a buscar cierta convergencia destro del mismo, el stress derivado del manejo de situaciones complejas o críticas, o el peligro de quedar subordinado a la influencia de una organización o un líder. Sus posibles ventajas radican en su mayor capacidad para acumular y procesar información, para establecer una eficaz división del trabajo, para atacar problemas complejos desde un punto de vista interdisciplinario, para estimar los riesgos desde un espectro más amplio de puntos de vista, y para identificar un mayor rango de opciones.

EI tercer nivel que interviene en el proceso de decisiones, con frecuencia en forma preponderante, es el de la dinámica organizacional y la política burocrática. Es este un tema con amplia trayectoria en las ciencias sociales, que escapa en mayor medida aún a las limitaciones de un ensayo preliminar como este. Las primeras ideas sobre las organizaciones burocráticas estaban vinculadas con su capacidad para desagregar tareas, establecer una buena división del trabajo y aplicar criterios de racionalidad al desempeño de esas tareas (Weber) o para encuadrar la irracionalidad o la emotividad individual (Freud). Estas ideas posteriormente han sido extensamente revisadas, acuñándose poco a poco y desde las vertientes más variadas el concepto de "política burocrática" cargado de nuevas connotaciones entre las cuales juegan un papel central las características de jerarquización, especialización y centralización de este tipo de organizaciones -inicialmente consideradas ventajosas- como posibles fuentes de distorsión en el proceso de recopilación de información, obtención de asesoramiento y adopción de decisiones ${ }^{42}$. Ello es probablemente la consecuencia del crecimiento de las organizaciones burocráticas en el mundo contemporáneo. La proliferación de intereses en el plano nacional e internacional, el creciente entrelazamiento entre ellos, la necesidad de que en su manejo intervenga un número cada vez mayor de agencias, la proyección externa que ha adquirido un número cada vez más elevado de ella (más de treinta agencias principales en Washington), y el consiguiente desdibujamiento -ya anotado- entre política interna e internacional, contribuyen a crear una verdadera maraña burocrática. Esto genera un crecimiento exponencial de las necesidades de división y delegación del trabajo; interacción, consulta y coordinación entre las distintas agencias; competencia entre ellas o erosión de sus responsabilidades por la intervención de otras, y de utilizar la negociación y el consenso para poder adoptar ciertas decisiones ${ }^{43}$.

Si este fenómeno se observa no ya desde el punto de vista de la interacción entre las distintas agencias, sino de la dinámica interna

सTilensky, Organization and Intelligence (Basic Books, 1967).

"Ver G. T. Allison, Essence of Decision, op. cit., $y$ M. Halpering, Bureaucratic Politics and Foreign Policy (Washington: Brookins Institution, 1974). 
de cada una de ellas, la tendencia central es la preferencia de cada organización a aplicar sus propias tradiciones, experiencias, valores, estilos, objetivos y procedimientos. La capacidad de procesar y analizar la información fue propuesta al comienzo de esta sección como el parámetro que permitiría distinguir una actitud más pasiva, más prejuiciada o más analítica frente a cada problema. La cansecuencia de las características desarrolladas por las organizacionès burocráticas tiende a buscar los datos, efectuar loi diagnósticos, identificar las opciones, apreciar los méritos o riesgos de las mismas, anticipar la reacción de los demás actores, y establecer sistemas de evaluación de las acciones emprendidas, que sean coherentes con sus propias visiones parroquiales. Otras limitaciones derivan de que frecuentemente entre sus métodos de negociación se cuentan la simplificación o la exageración de. los problemas, la búsqueda de compromisos a niveles inferiores a fin de asegurar una decisión en los escalones más altos; las compensaciones (trade-offs) entre distintos departamentos con el objeto de dar solución a un problema; la rigida aplicación de las rutinas establecidas, y un enorme consumo de tiempo y recursos. Entre las consecuencias de una política organizacional y burocrática se, cuenta el peligro de que las decisiones respondan más a los intereses de la organización que a los problemas que se busca resolver con ellas. Satisfacer los distintos intereses burocráticos puede traducirse en la ausencia de política, en fórmulas de compromiso, en una política de papel, o en una línea de conducta carente de liderazgo, débil o errática. El predominio de la organización en los servicios diplomáticos crea la necesidad de tratar con interlocutores más compartimentalizados y complejos; también hace más difícil enviar y. recibir mensajes coherentes, y hace muy complicado identificar los interlocutores apropiados para cada tema.

\section{Modelos, incertidumbre y previsión}

Entre los múltiples aspectos relevantes para el análisis de la política exterior que escapan a los límites de este ensayo vamos a escoger, para concluir, los tres anteriormente mencionados. Todos ellos están relacionados con los problemas más fundamentales que dificultan la realización de ese ejercicio. Uno consiste en la tendencia de los diplomáticos a analizar las situaciones que afectan la política exterior de su país caso por caso y sobre la base de sus propios méritos, empleando antecedentes extraídos del vasto anecdotario dip'omático, jurídico e histórico de que casi siempre disponen, y rehusando el poner ese análisis dentro de un contexto más amplio y sistemático. Otro consiste en confiar excesivamente en que esos precedentes, las rutinas diplomáticas y la forma en que normalmente se desarrollan las cosas, tenderán siempre a repetirse en la evolución de las relaciones externas del país, lo que los deja inermes frente a 
un caso caracterizado por la incertidumbre o a una situación excepcional, emergente o crítica. El uso de modelos o de métodos para paliar Ia incertidumbre o anticipar tendencias procuran reducir estos probiemas.

Se ha dicho que todos somos constructores de modelos en el sentido de que todos tenemos "marcos de referencia básicos", derivados de nuestra formación, experiencias y circunstancias, en términos de los cuales interpretamos la realidad, formulamos nuestras preguntas y buscamos respuestas para ellas. Naturalmente, aquí hablamos de modelos más formalizados. Se ha señalado que éstos presentan múltiples ventajas, como la de permitir tomar en cuenta relaciones de interdependencia complejas, inaccesibles al razonamiento no formalizado, y la de constituir poderosos instrumentos para acumular información y conocimientos que, procesados por la computadora, permiten formular proyecciones relativas a una enorme variedad de situaciones y de hipótesis con rapidez inusitada. También se han levantado críticas contra el uso de modelos, en el sentido de que éstos constituyen representaciones parciales o sesgadas de la rëalidad, que privilegian ciertas variables en desmedro de otras; de que representan necesariamente una visión conservadora o rígida del porvenir, debido a que sus predicciones tienden a quedar congeladas mientras no se alteren las variables incorporadas al modelo, Ios datos recogidos en relación con cada una de ellas o el peso rélativo asignado a unas y otros. También se ha dicho que son "cajas. negras" a las cuales apenas tienen acceso los expecialistas ${ }^{44}$.

En términos generales existen tres categorías de modelos. Los primeros se acercan al concepto de "tipo ideal" acuñado por Max Weber, y constituyen construcciones mentales referentes a entidades que no existen en la vida real pero que nos ayudan a entenderla por comparación, contraste o aproximación a dichos elementos: estos elementos pueden presentarse en forma de dicotomías, entre las cuales se ubica la realidad concreta (como la autoridad carismática y burocrática de Weber o las cinco opciones o variab es en torno a las cuales giraba el comportamiento de los individuos en una sociedad tradicional y otra moderna, según Parsons) o en formas químicamente puras de comportamiento con las cuates la realidad no se identifica nunca del todo (como la competencia perfecta en economfa o la racionalidad pura en teoría de las decisiones). La segunda categoría está integrada por modelos descriptivos que intentan representar las formas en que se comportan, interactúan y se relacionan las distintas variables involucrađas en una situación o en un proceso, un sistema que requiere un grado creciente de selectividad, simplificación y generalización mientras más complejos sea ese pro-

«P. Dubois, "Modelos Macroeconómicos y Planificación en un Porvenir Incierto", doc. de ILPES, 1986. 
ceso, y por lo tanto genera una distancia creciente entre el modelo y la realidad conforme se amplía el fenómeno estudiado. El tercer grupo incluye modelos prescriptivos que, en función de los valores $e$ intereses en juego en una situación dada, procuran déterminar cómo se debe actuar para alcanzar esos valores más que describir la situación como es.

Otra manera de categorizar los modelos que pueden emplearse en el análisis político, consiste en contrastar el enfoque "racional" de Herbert Simon con el enfoque "incrementalista" de Gharles Lindblom, y otros a los cuales ya se ha hecho referencia anteriormente.

Uno de los propósitos del uso de modelos en el análisis político apunta a reducir la incertidumbre, tan esencial en esta esfera de la vida social. En este sentido, junto con subrayar la importancia de analizar las tendencias o regularidades observables en el sistema internacional, resulta indispensable señalar la necesidad de disponer de conceptos y métodos de análisis que permitan examinar el papel de Ia incertidumbre en el funcionamiento del sistema $y$, sobre todo, reducirlo ${ }^{45}$. Prever el porvenir y anticjpar tendencias se ha vuelto mucho más difícil en ùn período turbulento y cambiante como el que atraviesan actualmente las relaciones internacionales que durante aquella etapa de crecimiento rápido, constante y predecible que caracterizó el período de postguerra. De aquí la importancia de estas técnicas.

EI valor de las proyecciones y los límites de la capacidad de predicción que ofrecen los distintos sistemas elaborados con este objeto; el carácter uni o multidireccional de las principales tendencias en el sistema internacional; el origen, el papel y las diferentes consecuencias de las crisis, emergencias o conflictos; el rol del azar o la fortuna en los resultados de la política exterior y en la evolución de las relaciones internacionales; el empleo de instrumentos tales como la teoría de los juegos para anticipar en parte la reacción de los interlocutores frente a determinadas situaciones o el impacto de acontecimientos imprevistos en las diversas partes involucrados en ellos, constituyen otras tantas técnicas que es posible considerar.en este campo ${ }^{48}$. Se ha analizado también el papel de la personalidad, Ia audacia o el coraje, y el de la iniciativa, la sorpresa o de los gestos retóricos deliberadamente calculados, en la configuración y el manejo de determinadas situaciones ${ }^{47}$.

El período actual se caracteriza por la incertidumbre o la turbu-

A. E. Woodman, The Unexpected in the International System, in Governance of the Western Hemisphere (The Aspen Institute, 1982).

${ }^{18} \mathrm{~L}$. Ingelstam, "La Planificación del Desarrollo a Largo Plazo: Notas sobre su Esencia y Metodologia", doc. de ILPES, 1986.

"Ver, N. Mandelbaum, "The Luck of the President", Foreign Affairs, vol. 64, N9 3, 1985. 
lencia del escenario internacional. Los últimos quince años están jalonados de fallas cometidas por analistas y polfticos por igual en lo que se refiere a anticipar el alza de los precios del petróleo o la crisis de pago de la deuda en 1973 y 1982, en el terreno económico, - la caída del Sha de Irán o de Somoza en Nicaragua, y en prepararse para enfrentar las consecuencias de estos eventos. Esta misma falla explica el auge que han tenido tanto los análisis de riesgos como los estudios prospectivos durante los últimos años.

La calidad de estos análisis se ha visto comprometida porque a menudo ellos oscilan entre un esfuerzo ad hoc, de carácter no sistemático, por entregar predicciones basadas en una mezcla de periodismo y de ciencia ficción (la prospectiva popular) y otros influenciados por la revolución behaviorista, más interesados en aislar pequeños fragmentos de la realidad suceptibles de mensura y de anticipar su comportamiento, por irrelevante que fuere, que en poder decir algo sobre los escenarios más complejos que son los que verdaderamente importan a los que toman las decisiones y de los cuales esos fragmentos son una parte. Esta opción entre los extremos del periodismo y el cientifismo no es por cierto necesaria y afortunadamente han habido intentos más serios que los anteriores de seguir un camino intermedio.

Tres son las principales funciones que desempeñan los pronósticos. La primera, que no parece corresponder al método prospectivo pero es condición para aplicarlo, consiste en entender la estructura y el funcionamiento del sistema poplítico y/o económico cuya evolución y comportam:ento se trata de anticipar. La segunda se refiere a anticipar las decisiones políticas que adoptará el gobierno o el comportamiento de determ:nadas variagles de la economía, tomando en cuenta los antecedentes disponibles y las disposiciones de los diversos grupos que pueden influir en estos eventos. La tercera consiste en construir posibles futuros alternativos con base en el conocimiento de la realidad y las tendencias históricas del país en cuestión y de las predicciones elaboradas acerca del comportamiento probable de las principales variables políticas y económicas ${ }^{48}$. Estos escenarios permiten anticipar, con un cambiante margen de probabilidad, la existencia de un clima favorable o adverso a determinado tipo de vinculaciones (alianzas militares, comercio, inversiones directas), la posibilidad de que prevalezcan relaciones de cooperación o de conflicto, y la dirección, el grado y la energía con que otros gobiernos pueden formular sus políticas u orquestar sus reacciones (cumplimiento de sus compromisos con los aliados, políticas de expansión comercial o adopción de medidas proteccionistas).

${ }^{*}$ W. Ascher, y W. Overhold, Strategic Planning and Forescasting: Political Risk and Economic Opportunity (John Willen and Sons, 1983) y W. H. Overhold, Political Risk (Euromoney Publications, 1982). 
Muchos de los estudios prospectivos de mayor renombre elaborados en los últimos años no coinciden exactamente con este tipo de ejercicios pero suministran una buena base para anticipar ciertas tendencias o comportamientos. Por lo tanto, deben formar parte de los esfuerzos encaminados a anticipar los escenarios en que tendrá que desenvolverse la política exterior en el futuro mediano ${ }^{49}$.

En todo caso, se trata de una disciplina difícil, que como ya se ha dicho oscila permanentemente entre la tentación de trabajar con las herramientas de la intuición o con los más sofisticados métodos cuantitativos; de la cual con frecuencia se esperan predicciones infalibles sobre acontecimientos muy precisos como revoluciones, golpes de Estado, resultados electorales, evaluaciones o aumento de las tasas de interés, y que tiene en su contra el pasado, permanente testigo de sus errores. Pero, a pesar de ellos, interpretar las tendencias y anticipar el porvenir es necesario.

Como advertimos en el prólogo, este ensayo tenía el limitado propósito de relevar algunos de los elementos que es necesario tomar en cuenta en el análisis de la política exterior. Quisiéramos concluír con algunas reflexiones. Aunque el análisis y la planificación de la política exterior efectuados sobre bases exclusivamente intuitivas y casuísticas es completamente insuficiente, y cada vez se hace más necesario emplear sistemas de análisis más rigurosos, en última instancia no hay nada que pueda sustituir a la intuición y el juicio. Si bien los métodos que se han ensayado para anticipar el futuro están sujetos a grandes márgenes de error y con frecuencia prometen más de lo que entregan, es necesario tener una cierta interpretación de las tendencias predominantes en las relaciones internacionales y una visión de los escenarios que podrían prevalecer en el futuro. Aun cuando los esfuerzos para reducir los márgenes de incertidumbre o para disponer de respuestas alternativas eficaces a situaciones imprevistas o a crisis son muy importantes, en la mayoría de los casos, más importante aún es continuar sustentando la planificación de la política exterior sobre antecedentes basados en peróodos de normalidad y en la prospección de las tendencias dominantes del sistema, más que en las excepciones (no olvidemos que la ausencia de una política exterior -o la imposibilidad de tener una- suele fomentar las emergencias). Y aunque una vez definidos los intereses de un pads en sus relaciones exteriores existe una serie de métodos para traducirlos en objetivos, jerarquizarlos y definir cursos de acción alternativos, lo más importante es siempre la correcta definición de esos intereses.

\footnotetext{
๑Ver, por ejemplo, D. H. Meadows y otros, The Limits to Growth (Potomac Associates, 1972); H. Kahn, World Economic Development (Morrow-Quill, 1979) $y$ OECD, Facing the Future (1979).
} 
Luciano Tomassini / Elementos para el análicis de la politica exterior

"Todo proceso de planificación, sea para una empresa, una región o una nación, tiene que comenzar por encontrar y definir cuál es la clase de 'problemática' que realmente tiene que encarar. La experiencia revela que la función más importante de la planificación, en retrospectiva, ha sido casi siempre el esfuerzo por aislar los 'problemas esenciale;' de todas las demás preocupaciones"øo.

n. Ingelstam, op. cit., p. 3. 